\title{
Role of Ion Channels in Ductus Arteriosus Closure
}

Toru Akaike and Susumu Minamisawa*

Department of Cell Physiology, Jikei University School of Medicine, Tokyo, Japan

\begin{abstract}
The Ductus Arteriosus (DA) is a normal and essential fetal structure that connects the main pulmonary artery and the descending aorta. The DA constriction which occurs immediately after birth is triggered by: (a) an increase in oxygen tension, (b) a dramatic decline in circulating $\mathrm{PGE}_{2}$ and a promotion of its degradation in the lung, (c) a decrease in the expression of PGE receptors in the DA wall and (d) a decrease in blood pressure within the DA. Ion channels play an essential role in this acute response that is known as functional DA closure. Oxygenation from fetal to neonatal circulation inhibits several potassium channels (voltage-dependent and ATP-dependent), which then leads to membrane depolarization. This depolarization triggers the activation of voltage-dependent calcium channels, and extracellular calcium then enters into the cytosol of smooth muscle cells of the DA. Calcium is also released from the sarcoplasmic reticulum, with a consequent supply provided through store-operated calcium channels. An increase in cytosolic calcium induces DA constriction. Ion channels also play a role in vascular remodeling of the DA, although this has not yet been extensively investigated. Voltage-dependent $L$ - and T-type calcium channels promote formation of intimal thickening through an increase in proliferation and migration of DA smooth muscle cells. Current medical treatment for patients with persistent patent DA is limited to cyclooxygenase inhibitors such as indomethacin and ibuprofen. A better understanding of the role of ion channels in vasoconstriction and vascular remodeling of the DA may encourage the design and development of novel pharmacological treatments for patients with patent DA. In this review, we focus on current knowledge on the roles of ion channels in the DA.
\end{abstract}

Keywords: Ion channels; Calcium; Potassium; Oxygen; Vascular remodeling; Contraction; Ductus Arteriosus (DA)

\section{Clinical Background of Patent Ductus Arteriosus}

The ductus arteriosus (DA), an essential fetal artery that connects the main pulmonary artery and the descending aorta, closes spontaneously within a few days after birth. The primary driving force behind DA closure is an increase in oxygen tension and a decline in circulating prostaglandin $\mathrm{E}_{2}\left(\mathrm{PGE}_{2}\right)$ [1-3]. When the DA remains open after the first 3 days of life, the resulting condition is known as patent ductus arteriosus (PDA). The incidence of PDA unaccompanied by any other cardiovascular abnormality has been estimated to be $0.06 \%$ of term infants [4]. Nevertheless, the incidence sharply increases in premature infants. Symptomatic PDA cases have been found in $28 \%$ of very-lowbirth-weight infants $(<1500 \mathrm{~g})$ and $55 \%$ of extremely-low-birth-weight infants $(<1000 \mathrm{~g})[5,6]$. The presence of PDA significantly increases life-threatening risks in preterm infants, such as pulmonary edema and deterioration of respiratory status, which further decreases oxygen tension in these infants and keeps the DA open. Although oxygen is a potent vasoconstrictor of the DA, a high concentration of oxygen inhalation is prohibited in low-birth-weight infants because of the risk of oxygen-mediated tissue injury such as retinopathy. Pharmacological treatment of PDA has been limited to cyclooxygenases (COX) inhibitors such as indomethacin and ibuprofen.

\section{Overview of the Mechanism of DA Closure}

Mammalian DA closure, including that in humans, is thought to occur due to a combination of two different mechanisms. One is an acute response of smooth muscle constriction within the first several hours of life, known as functional closure of the DA. The other is a relatively chronic response of structural change in the DA during the prenatal period, known as anatomical closure of the lumen [7-9]. Progression of neointimal thickening represents a significant structural change during late gestation and the first several days of life. After shutting down blood flow, progressive apoptosis and fibrotic changes occur in the DA, resulting in permanent DA closure and a remnant structure known as the ligamentum arteriosum. Although this process is similar among mammalian DA, the time course of the two mechanisms varies between species. The DA constriction immediately after birth is triggered by: (a) an increase in oxygen tension, (b) a dramatic decline in circulating $\mathrm{PGE}_{2}$ and a promotion of its degradation in the lung, (c) a decrease in the expression of PGE receptors in the DA wall, and (d) a decrease in blood pressure within the DA $[7,8]$. Endothelin-1, nitric oxide (NO), norepinephrine, acetylcholine, thromboxane A2, and bradykinin have been proposed as potential vasoreactive agents, in addition to oxygen and PGE [10-19].

Anatomical closure of the DA is associated with the distinct differentiation of the vessel wall. Intimal thickening is the most prominent phenotypic change and involves several processes: (a) an area of subendothelial deposition of an extracellular matrix, (b) the disassembly of the internal elastic lamina and the loss of elastic fiber in the medial layer, and (c) the migration of undifferentiated medial smooth muscle cells (SMCs) into the subendothelial space. Finally, the DA permanently closes, and the remnant of the DA is known as the ligamentum arteriosum in adults [7].

\section{Pharmacological Treatment of PDA}

In terms of medical treatment for patients with PDA, nonselective COX inhibitors such as indomethacin and ibuprofen, which inhibit

*Corresponding author: Susumu Minamisawa, Department of Cell Physiology, Jikei University School of Medicine, 3-25-8 Nishi-Shimbashi, Minato-ku, Tokyo 105-8461, Japan, Tel: +81-(0)3-3433-1111; Fax: +81-(0)3-3433-1279; E-mail: sminamis@jikei.ac.jp

Received August 24, 2013; Accepted November 16, 2013; Published January10, 2014

Citation: Akaike T, Minamisawa S (2014) Role of Ion Channels in Ductus Arteriosus Closure. Human Genet Embryol 3: 116. doi:10.4172/2161-0436.1000116

Copyright: (C) 2014 Akaike T, et al. This is an open-access article distributed under the terms of the Creative Commons Attribution License, which permits unrestricted use, distribution, and reproduction in any medium, provided the original author and source are credited. 
$\mathrm{PGE}_{2}$ synthesis, are the only available pharmacological agents at present. Since the discovery of this effect more than 35 years ago, no medication for PDA has been developed [20,21]. The efficiency of COX inhibitors depends on gestational age. Although indomethacin is an effective treatment for term infants with symptomatic PDA, it is less effective in preterm infants because of inadequate DA contraction [20-22]. Recently, it has been suggested that one of the causes of such low efficiency is undeveloped intimal cushion formation [9]. Chronic activation of the $\mathrm{PGE}_{2}$ receptor EP4 promotes the production of hyaluronic acid, an extracellular matrix, which induces SMC migration into the subendothelial layer [9]. In fact, COX-1/2 double knockout mice exhibit persistent PDA [23]. No less important is the fact that COX inhibitors have critical adverse effects, in addition to their low efficiency. It has been reported that premature infants with symptomatic PDA are at risk for necrotizing enterocolitis, renal failure, chronic lung disease, pulmonary hemorrhage, and intraventricular hemorrhage [24]. The postnatal use of the COX inhibitors may also increase the risk of intestinal perforation and renal failure [25-28]. Therefore, a new therapeutic agent for preterm infants with PDA is needed. To develop a new strategy of medical treatment in patients with PDA, it is extremely important to first understand the precise molecular mechanisms underlying both functional and anatomical DA closure. Although the modulation of anatomical DA closure should be considered in future therapeutic strategies for PDA, controlling the vascular tone of the DA could feasibly aid in the discovery of a new strategy for treatment of PDA at present, because the fundamental mechanism of functional closure of the DA has been intensively investigated. At birth, functional closure of the DA is mainly initiated by an oxygen-induced vasoconstrictor mechanism. Although endothelium-derived relaxing and constricting factors such as prostaglandins and endothelin are known to play an important role in regulating DA tone, oxygen constricts the DA in the absence of endothelium, suggesting that the core of the oxygensensing mechanism largely depends on the intrinsic character of DA SMCs $[10,29,30]$. It has been known that specific ion channels in the sarcolemma work as oxygen sensors or effectors. Therefore, in the present review, we will focus on the ion channels involved in functional closure of the DA, and especially on their oxygen-sensing mechanisms.

\section{Oxygen-Induced Contraction and Ion Channels}

It has been proposed that an increase in oxygen tension is the most potent vasoconstrictive factor of the DA after birth. The lumen of the DA is perfused by blood with a $\mathrm{PO}_{2}$ of about $18 \mathrm{mmHg}$ in the fetal lamb [31]. Arterial $\mathrm{PO}_{2}$ rapidly increases to $90-100 \mathrm{mmHg}$ after birth. Kennedy and Clark were the first to demonstrate that the DA is constricted by oxygen [32]. Although most vascular smooth muscles contract in response to an increase in oxygen tension, the response of the DA to oxygen is much greater in magnitude [31]. This response is due to the DA having developed a specialized oxygen-sensing system. Interestingly, this high sensitivity of the DA to oxygen is related to development in mammalian fetus and chick embryos [33,34]. The premature DA did not constrict even when $\mathrm{PO}_{2}$ was raised to over 500 mmHg in lambs at less than 80 days' gestation (full term gestation in the lamb is around 150 days). The intrinsic maturation of DA SMCs, including the functional development of a certain ion channel, is required for the oxygen sensing mechanism. Importantly, Roulet and Coburn demonstrated that the oxygen-induced contraction of the guinea pig DA was associated with SMC depolarization [35]. Furthermore, an increase in oxygen tension inhibits the entire cell potassium current, suggesting that potassium channels play an important role in the high sensitivity of the DA to oxygen. Most studies suggest that voltagedependent potassium channels ( $\mathrm{Kv}$ channels) are responsible for

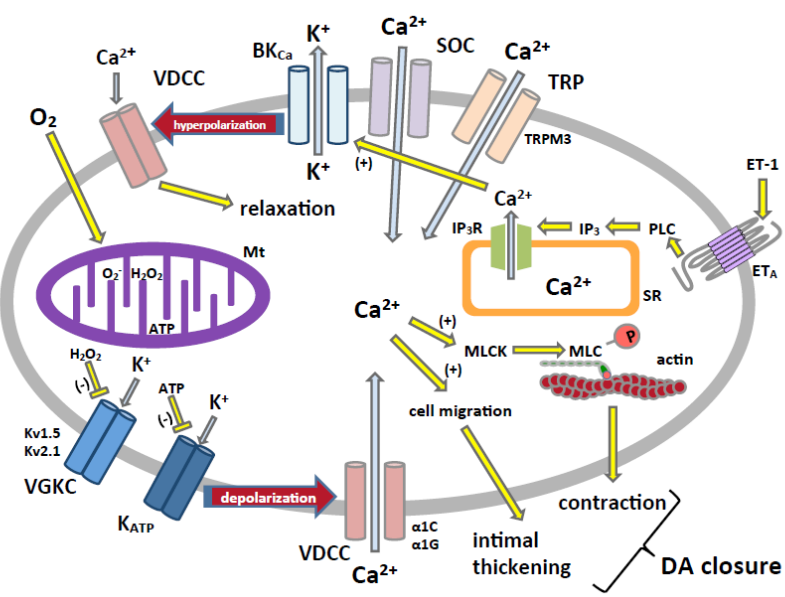

$\mathrm{K}^{+}$: potassium ion, $\mathrm{Ca}^{2+}$ : calcium ion, $\mathrm{O}_{2}$ oxygen, $\mathrm{O}_{2^{-}}$: superoxide anion, $\mathrm{H}_{2} \mathrm{O}_{2}$ : hydrogen peroxide, ATP: Adenosine Triphosphate, ET-1: Endothelin-1, ETA: Endothelin A receptor, PLC: Phospholipase C, IP3: Inositol Triphosphate, IP3R: IP3 receptor, MLCK: Myosin Light Chain Kinase, MLC: Myosin Light Chain, $\mathrm{Kv}$ : Voltage gated potassium channel, $\mathrm{K}_{\text {ATP }}$ : ATP-sensitive potassium channel, BK[Ca]: Large-conductance voltage-dependent and calcium-activated potassium channels, VDCC: Voltage-dependent calcium channel, SOC: Storeoperated calcium channel, TRP: Transient receptor potential channel, Mt: mitochondria, SR: sarcoplasmic reticulum

Figure 1: A schematic model of DA closure via ion channels.

oxygen's effect on membrane depolarization [30,36,37]. Interestingly, in SMCs of the resistant pulmonary arteries, hypoxia inhibits the potassium current and depolarizes the cell membrane, resulting in calcium entry via voltage-dependent L-type calcium channels, which is the same process seen in oxygen-induced contraction of the DA [38]. The precise mechanism behind these two tissue types oppositely sensing oxygen and then making use of similar effectors has not been fully understood (Figure 1).

ATP-sensitive potassium channels ( $\mathrm{K}_{\text {ATP }}$ channels) have also been implicated as oxygen sensors [39]. Inhibition of the potassium current causes membrane depolarization, resulting in an activation of voltagedependent L-type/T-type calcium channels and a subsequent increase in intracellular calcium [2].

Intracellular calcium is also increased by calcium release from the sarcoplasmic reticulum (SR) via the phospholipase C (PLC)-inositol triphosphate (IP3) signal pathway in DA SMCs. Furthermore, the release of calcium from the IP3-sensitive store in the SR due to oxygen promotes calcium entry through store-operated calcium channels in the sarcolemma [40]. Accordingly, many channels and transporters in DA SMCs are believed to be involved in oxygen-induced DA constriction.

Intracellular calcium conjugates calmodulin activates myosin light chain kinase (MLCK), which is a specialized calciumcalmodulin dependent kinase II. Phosphorylated myosin light chain (MLC) by MLCK causes an actin-myosin interaction, resulting in ATP-dependent muscle contraction. MLC phosphatase then dephosphorylates the phosphorylated MLC and releases the actinmyosin interaction, resulting in relaxation. Intracellular calcium is excluded from the cell through the sodium-calcium exchanger in the plasma membrane and is also loaded into the SR though the SR calcium pumps (SERCA) [41-43]. Finally, the effect of the rise in cytosolic calcium is amplified by enhanced calcium sensitivity of the actin-myosin interaction in the DA. Rho-kinase is believed to play 
a critical role in higher calcium sensitivity in the DA [44], which is, unfortunately, beyond the scope of this review.

\section{Channels}

\section{Voltage gated potassium channel (Kv1.5, Kv2.1)}

Several studies have demonstrated that 4-aminopyridine (4-AP)sensitive, voltage gated potassium channels $(\mathrm{Kv})$ play a central role in oxygen-induced constriction in the DA $[30,45,46]$. At the molecular level, potassium channels are composed of pore-forming $\alpha$-subunits which co-assemble with cytoplasmic regulatory/auxiliary -subunits. Both $\mathrm{Kv}$-subunits (Kv1.2, Kv1.5, Kv2.1, Kv3.1, Kv4.2, Kv4.3, and Kv9.3) and $\mathrm{Kv}$-subunits have been shown to possess oxygen sensing capabilities [47]. Among them, Kv1.2, Kv1.5, and Kv2.1 are the predominant Kvasubunit in the human DA, and $\mathrm{Kv} \gamma 1.2$ is a predominant $\mathrm{Kv} \beta$-subunit in the pig DA $[37,48,49]$. Michelakis et al. demonstrated that rotenone and antimycin, mitochondrial electron transport chain inhibitors, decreased diffusible redox-mediator $\left(\mathrm{H}_{2} \mathrm{O}_{2}\right)$ production and increased potassium current through $\mathrm{Kv}$ channels, resulting in relaxation of oxygen-induced constriction of the DA [48]. They also demonstrated that $\mathrm{H}_{2} \mathrm{O}_{2}$, like oxygen, inhibited potassium currents and depolarized DA SMCs. They then concluded that oxygen increases the production of $\mathrm{H}_{2} \mathrm{O}_{2}$ through activating the mitochondrial electron transport chain complexes I or III and then inhibiting $\mathrm{Kv}$ channel activity in the DA [45,46,48-50].

In contrast with the full term DA, the immature DA is less likely to constrict in response to oxygen at a physiological concentration $[49,51,52]$. Waleh et al. demonstrated that Kv channels appear to be the only potassium channels that oppose ductus tension in the mature DA [53]. The poor response of the DA to oxygen could be related to ionic immaturity, i.e., reduced expression and function of oxygen- and 4-AP-sensitive Kv channels. In humans, the expression levels of Kv1.2 and Kv2.1 proteins are lower in preterm than in term foetuses [49]. Importantly, in vivo transfer of the gene for Kv1.5 or Kv2.1 partially restores the contractive capabilities of oxygen in the DA of the preterm rabbit [51]. These results suggest that modulating the vascular tone through the oxygen-sensitive $\mathrm{Kv}$ channels offers a novel therapeutic target in preterm infants.

Recently, Fan et al. demonstrated that $\mathrm{PGE}_{2}$ increased the potassium current through the $\mathrm{PGE}_{2}$-specific receptor EP4, which led to vasorelaxation in the preterm rabbit DA [49]. This result indicates that the $\mathrm{PGE}_{2}$-EP4 signal promotes vasorelaxation not only by activation of MLC phosphatase but also by an increase in potassium current .

\section{ATP-sensitive potassium channels $\left(K_{\text {ATP }}\right)$}

ATP-sensitive potassium channels play an important role in maintaining membrane resting potential. After birth, an increase in oxygen tension produces intracellular ATP more through oxidative phosphorylation in mitochondria, which closes ATP-sensitive potassium channels and then induces membrane depolarization in the DA. Nakanishi et al. demonstrated that glibenclamide, a second generation sulfonylurea that inhibits ATP-sensitive potassium channels, contracted the isolated rabbit DA exposed to fetal oxygen tension. In addition, cromakalim, an ATP-sensitive potassium channel activator, relaxed the oxygen-induced DA contraction [39]. Waleh et al. suggested that ATP-sensitive potassium channels play a role in only the immature DA, but not in the mature DA in sheep fetuses [53]. Nevertheless, maternal administration of tolbutamide and chlorpropamide, which are first generation sulfonylureas that can pass through placenta, contracted the full term rat DA up to $50 \%$ (personal communication with Dr. Kazuo Momma). On the contrary, Ågren et al. demonstrated that glibenclamide had no effect on the chick DA at any developmental stage [33]. Therefore, the role of ATP-sensitive potassium channels may differ among species. In humans, the role of ATP-sensitive potassium channels has not yet been investigated. Recently, a gene mutation of SUR2 has been identified to cause Cantu syndrome, which exhibits a PDA phenotype at a low frequency [54,55]. Although the effect of the SUR2 gene mutation has not been demonstrated in the DA, mutations in SUR2 attenuate the inhibitory effect of ATP-sensitive potassium channel currents, resulting in channel opening [54]. This genetic data implicates that the $\mathrm{K}_{\text {ATP }}$ channel plays a role in the closure of the human DA. Also, it is reported that PGE ${ }_{2}$ and endothelin-1 (ET-1) is associated with the ATP-sensitive potassium channel. Glibenclamide inhibits the fetal lamb DA relaxation induced by M\&B-28767, which

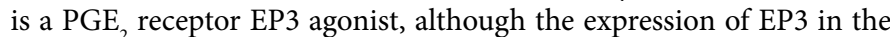
DA is not abundant [56]. ET- 1 and PKC activators, such as phorbol-12, 13-dibutyrate and 1-olelyl-2-acetyl-sn-glycerol, reduce the ATPsensitive potassium channel current in pulmonary artery (PA) SMCs [57]. Nevertheless, further studies are needed to understand whether these regulatory factors of ATP-sensitive potassium channels play a role in DA closure.

\section{Large-conductance voltage-dependent and calcium-activated potassium channels (BK[Ca])}

In addition to $\mathrm{Kv}$ and $\mathrm{K}_{\mathrm{ATP}}$ channels, several recent studies have demonstrated that large-conductance voltage-dependent and calciumactivated potassium channels (BK[Ca]) may regulate the vascular tone of the DA. BK[Ca] channels are known to be abundantly expressed in vascular SMCs, including the premature rat DA [58]. Although several studies have indicated that $\mathrm{BK}[\mathrm{Ca}]$ channels respond to oxygen, $\mathrm{BK}[\mathrm{Ca}]$ is unlikely to be involved in oxygen-induced ductal constriction [48,5860]. Alternatively, activation of $\mathrm{BK}[\mathrm{Ca}]$ channels may play a role in countering relaxation for the oxygen-induced contraction after birth or hypercarbic acidosis-induced relaxation $[58,61]$.

\section{Voltage-dependent L-type calcium channels (L-type VDCC)}

Calcium entry through voltage-dependent calcium channels increases intracellular calcium, resulting in vessel contraction by phosphorylation of MLC. Oxygen activates voltage-dependent L-type calcium channels, leading to DA constriction in term rabbit DA [30,36]. Takizawa et al. demonstrated that the L-type VDCC blocker verapamil inhibits the spontaneous closure of the DA in newborn rats [62] Cav1.2 is a predominant isoform of voltage-dependent L-type calcium channels, and Cav1.2 is also expressed in the rat DA [63]. Thebaud et al. suggested that the immaturity of oxygen sensitivity in L-type calcium channels contributes to impaired oxygen-induced DA constriction in preterm rabbit DA [36]. Maturity of voltage-dependent L-type calcium channels is required for oxygen induced DA constriction. In this regard, our previous study demonstrated that maternal administration of vitamin A significantly increased the expression levels of Cav1.2 and Cav3.1 mRNAs in the rat DA [63]. In addition to the role of voltagedependent L-type calcium channels in the regulation of

vascular tone, we found that both L-type and T-type calcium channels promoted SMC proliferation in the DA, which may be involved in the formation of intimal thickening in the DA [63].

\section{Voltage-dependent T-type calcium channels (T-type VDCC)}

We, and other investigators, previously reported that calcium influx through voltage-dependent T-type calcium channels also promotes oxygen-induced DA closure $[39,64]$. We also found that oxygeninduced activation of voltage dependent T-type calcium channels, 
especially Cav3.1, promotes not only vascular constriction but also neointimal thickening via an increase in SMC migration in the DA [64]. Importantly, $\alpha 1 \mathrm{G}$, a Cav3.1 subunit, is predominantly expressed in the rat neonatal DA, and is significantly up-regulated in oxygenated rat DA tissues and SMCs [64]. These data imply that the regulation of T-type calcium channels is an alternative therapeutic target to selectively constrict the DA.

\section{Voltage-dependent sodium channels}

At present, there is no report demonstrating that voltage-dependent sodium channels are involved in DA closure. Instead, Clyman et al. have demonstrated that calcium influx and efflux through the sodiumcalcium exchanger regulates DA constriction $[65,66]$.

\section{Store-operated calcium (SOC) channels and transient receptor potential (TRP) channels}

Although calcium entry through voltage-dependent calcium channels plays a major role in oxygen-induced DA constriction after birth, intracellular calcium is also increased by the release of calcium from the IP3-sensitive store in the SR [67]. Hong et al. also found that significant normoxic contraction of the rabbit DA occurred in the presence of the $\mathrm{K}_{\mathrm{V}}$ channel blocker 4-AP and the $\mathrm{BK}[\mathrm{Ca}$ ] blocker TEA [40]. This depolarization-independent DA constriction is caused by the release of calcium from the IP3-sensitive store in the SR and subsequent calcium entry through store-operated calcium (SOC) channels [40]. The SOC current is thought to pass through transient receptor potential (TRP) channels [68]. In the sheep DA, inhibition of SR calcium-ATPase activates store-operated calcium channels in the presence of the L-type calcium channel blocker nifedipine, and then calcium influx from the extracellular space occurs, which contributes to DA constriction [65]. Lu et al. reported that TRPC1, TRPC4, and TRPC6 channels are abundant in pulmonary artery SMCs and are involved in store-operated calcium entry in response to hypoxia [69]. Hong et al. reported that TRPC1 and TRPC4 were identified in the DA by RT-PCR and Western blot analysis [40]. The role of TRPC1 and TRPC4 in oxygen-induced DA constriction requires further investigation.

\section{Closing Remarks}

Closure of DA occurs in two phases. During the first, several hours after birth in term neonates, there is a functional closure as a result of smooth muscle contraction of the DA via an increase in oxygen tension and a decline in circulating PGE $_{2}$. Ion channels, especially several potassium channels, play an essential role in this acute response that is known as functional DA closure. Oxygen inhibits potassium channels such as Kv1.5, Kv2.1, and $\mathrm{K}_{\mathrm{ATP}}$, resulting in membrane depolarization. Calcium entry through calcium channels such as L- and T-type voltagedependent calcium channels and store-operated calcium channels increase intracellular calcium, which induces DA constriction. In addition, ion channels also play a role in vascular remodeling of the DA. Voltage-dependent L- and T-type calcium channels promote formation of intimal thickening through an increase in proliferation and migration of DA SMCs. A better understanding of the role of ion channels in vasoconstriction and vascular remodeling of the DA should provide an opportunity to design and develop novel pharmacological treatments for patients with PDA.

\section{References}

1. Coceani F, Olley PM (1973) The response of the ductus arteriosus to prostaglandins. Can J Physiol Pharmacol 51: 220-225.

2. Leonhardt A, Glaser A, Wegmann M, Schranz D, Seyberth H, et al. (2003) Expression of prostanoid receptors in human ductus arteriosus. $\mathrm{Br} \mathrm{J}$ Pharmaco 138: 655-659.
3. Heymann MA, Rudolph AM (1975) Control of the ductus arteriosus. Physiol Rev 55: 62-78.

4. Hoffman JI, Kaplan S (2002) The incidence of congenital heart disease. J Am Coll Cardiol 39: 1890-1900.

5. Lee SK, McMillan DD, Ohlsson A, Pendray M, Synnes A, et al. (2000) Variations in practice and outcomes in the Canadian NICU network: 1996-1997. Pediatrics 106: $1070-1079$

6. Koch J, Hensley G, Roy L, Brown S, Ramaciotti C, et al. (2006) Prevalence of spontaneous closure of the ductus arteriosus in neonates at a birth weight of 1000 grams or less. Pediatrics 117: 1113-1121.

7. Smith GC (1998) The pharmacology of the ductus arteriosus. Pharmacol Rev 50: $35-58$.

8. Clyman RI (2006) Mechanisms regulating the ductus arteriosus. Biol Neonate 89: $330-335$

9. Yokoyama U, Minamisawa S, Quan H, Ghatak S, Akaike T, et al. (2006) Chronic activation of the prostaglandin receptor EP4 promotes hyaluronan-mediated neointimal formation in the ductus arteriosus. J Clin Invest 116: 3026-3034.

10. Shen J, Nakanishi T, Gu H, Miyagawa-Tomita S, Wu GR, et al. (2002) The role of endothelin in oxygen-induced contraction of the ductus arteriosus in rabbit and rat fetuses. Heart Vessels 16: 181-188.

11. Momma K, Nakanishi T, Imamura S (2003) Inhibition of in vivo constriction of fetal ductus arteriosus by endothelin receptor blockade in rats. Pediatr Res 53 : 479-485.

12. Momma K, Toyono M (1999) The role of nitric oxide in dilating the fetal ductus arteriosus in rats. Pediatr Res 46: 311-315.

13. Ovadia B, Bekker JM, Fitzgerald RK, Kon A, Thelitz S, et al. (2002) Nitric oxideendothelin-1 interactions after acute ductal constriction in fetal lambs. Am J Physiol Heart Circ Physiol 282: H862-871.

14. Knight DH, Patterson DF, Melbin J (1973) Constriction of the fetal ductus arteriosus induced by oxygen, acteylcholine, and norepinephrine in norma dogs and those genetically predisposed to persistent patency. Circulation 47 127-132.

15. Smith GC, McGrath JC (1991) Prostaglandin E2 and fetal oxygen tension synergistically inhibit response of isolated fetal rabbit ductus arteriosus to norepinephrine. J Cardiovasc Pharmacol 17: 861-866.

16. Smith GC (1997) The effect of passive stretch on the response of the fetal rabbit ductus arteriosus to indomethacin, noradrenaline and prostaglandin E2. Exp Physiol 82: 537-546

17. Schuurman MJ, Villamor E (2010) Endothelium-dependent contraction induced by acetylcholine in the chicken ductus arteriosus involves cyclooxygenase-1 activation and TP receptor stimulation. Comp Biochem Physiol A Mol Integr Physiol 157: 28-34

18. Yokota T, Aida T, Ichikawa Y, Fujita T, Yokoyama U, et al. (2012) Low-dose thromboxane A2 receptor stimulation promotes closure of the rat ductus arteriosus with minimal adverse effects. Pediatr Res 72: 129-136.

19. Bateson EA, Schulz R, Olley PM (1999) Response of fetal rabbit ductus arteriosus to bradykinin: role of nitric oxide, prostaglandins, and bradykinin receptors. Pediatr Res 45: 568-574.

20. Heymann MA, Rudolph AM, Silverman NH (1976) Closure of the ductus arteriosus in premature infants by inhibition of prostaglandin synthesis. $\mathrm{N}$ Engl J Med 295: 530-533

21. Friedman WF, Hirschklau MJ, Printz MP, Pitlick PT, Kirkpatrick SE (1976) Pharmacologic closure of patent ductus arteriosus in the premature infant. N Engl J Med 295: 526-529.

22. Takami T, Yoda H, Kawakami T, Yamamura H, Nakanishi T, et al. (2007) Usefulness of indomethacin for patent ductus arteriosus in full-term infants. Pediatr Cardiol 28: 46-50.

23. Loftin CD, Trivedi DB, Tiano HF, Clark JA, Lee CA, et al. (2001) Failure of ductus arteriosus closure and remodeling in neonatal mice deficient in cyclooxygenase-1 and cyclooxygenase-2. Proc Natl Acad Sci U S A 98: 1059 1064

24. Smyth JM, Collier PS, Darwish M, Millership JS, Halliday HL, et al. (2004) Intravenous indometacin in preterm infants with symptomatic patent ductus arteriosus. A population pharmacokinetic study. Br J Clin Pharmacol 58: 249-258. 
25. Van Overmeire B, Smets K, Lecoutere D, Van de Broek H, Weyler J, et al (2000) A comparison of ibuprofen and indomethacin for closure of patent ductus arteriosus. N Engl J Med 343: 674-681.

26. Watterberg KL, Gerdes JS, Cole CH, Aucott SW, Thilo EH, et al. (2004) Prophylaxis of early adrenal insufficiency to prevent bronchopulmonary dysplasia: a multicenter trial. Pediatrics 114: 1649-1657.

27. Attridge JT, Clark R, Walker MW, Gordon PV (2006) New insights into spontaneous intestinal perforation using a national data set: (1) SIP is associated with early indomethacin exposure. J Perinatol 26: 93-99.

28. Fowlie PW, Davis PG (2003) Prophylactic indomethacin for preterm infants: a systematic review and meta-analysis. Arch Dis Child Fetal Neonatal Ed 88: F464-466.

29. Coburn RF, Eppinger R, Scott DP (1986) Oxygen-dependent tension in vascular smooth muscle. Does the endothelium play a role? Circ Res 58: 341-347.

30. Tristani-Firouzi M, Reeve HL, Tolarova S, Weir EK, Archer SL (1996) Oxygeninduced constriction of rabbit ductus arteriosus occurs via inhibition of a 4-aminopyridine-, voltage-sensitive potassium channel. J Clin Invest 98: 19591965.

31. Rudolph AM (2009) Congenital Disease of the Heart: clinical physiological considerations (3rdedn). Wiley-Blackwell, USA.

32. Kennedy JA, Clark SC (1942) Observations on the physiological reactions of the ductus arteriosus. Am J Physiol 136: 140-147.

33. Agren P, Cogolludo AL, Kessels CG, Pérez-Vizcaíno F, De Mey JG, et al (2007) Ontogeny of chicken ductus arteriosus response to oxygen and vasoconstrictors. Am J Physiol Regul Integr Comp Physiol 292: R485-496.

34. Wu C, Hayama E, Imamura S, Matsuoka R, Nakanishi T (2007) Developmental changes in the expression of voltage-gated potassium channels in the ductus arteriosus of the fetal rat. Heart Vessels 22: 34-40.

35. Roulet MJ, Coburn RF (1981) Oxygen-induced contraction in the guinea pig neonatal ductus arteriosus. Circ Res 49: 997-1002.

36. The baud B, Wu XC, Kajimoto H, Bonnet S, Hashimoto K, et al. (2008) Developmental absence of the $\mathrm{O} 2$ sensitivity of L-type calcium channels in preterm ductus arteriosus smooth muscle cells impairs $\mathrm{O} 2$ constriction contributing to patent ductus arteriosus. Pediatr Res 63: 176-181.

37. Hayama E, Imamura S, Wu C, Nakazawa M, Matsuoka R, et al. (2006) Analysis of voltage-gated potassium channel beta1 subunits in the porcine neonatal ductus arteriosus. Pediatr Res 59: 167-174.

38. Weir EK, Olschewski A (2006) Role of ion channels in acute and chronic responses of the pulmonary vasculature to hypoxia. Cardiovasc Res 71: 630641.

39. Nakanishi T, Gu H, Hagiwara N, Momma K (1993) Mechanisms of oxygeninduced contraction of ductus arteriosus isolated from the fetal rabbit. Circ Res 72: $1218-1228$

40. Hong Z, Hong F, Olschewski A, Cabrera JA, Varghese A, et al. (2006) Role of store-operated calcium channels and calcium sensitization in normoxic contraction of the ductus arteriosus. Circulation 114: 1372-1379.

41. Dillon PF, Aksoy MO, Driska SP, Murphy RA (1981) Myosin phosphorylation and the cross-bridge cycle in arterial smooth muscle. Science 211: 495-497.

42. Ito M, Hartshorne DJ (1990) Phosphorylation of myosin as a regulatory mechanism in smooth muscle. Prog Clin Biol Res 327: 57-72.

43. Kim HR, Appel S, Vetterkind S, Gangopadhyay SS, Morgan KG (2008) Smooth muscle signalling pathways in health and disease. J Cell Mol Med 12: 21652180.

44. Kajimoto H, Hashimoto K, Bonnet SN, Haromy A, Harry G, et al. (2007) Oxygen activates the Rho/Rho-kinase pathway and induces RhoB and ROCK-1 expression in human and rabbit ductus arteriosus by increasing mitochondriaderived reactive oxygen species: a newly recognized mechanism for sustaining ductal constriction. Circulation 115: 1777-1788.

45. Michelakis E, Rebeyka I, Bateson J, Olley P, Puttagunta L, et al. (2000) Voltagegated potassium channels in human ductus arteriosus. Lancet 356: 134-137.

46. Reeve HL, Tolarova S, Nelson DP, Archer S, Weir EK (2001) Redox control of oxygen sensing in the rabbit ductus arteriosus. J Physiol 533: 253-261.

47. Yuan JX (2001) Oxygen-sensitive $\mathrm{K}(+)$ channel(s): where and what? Am J Physiol Lung Cell Mol Physiol 281: L1345-1349.
48. Michelakis ED, Rebeyka I, Wu X, Nsair A, Thébaud B, et al (2002) O2 sensing in the human ductus arteriosus: regulation of voltage-gated $\mathrm{K}+$ channels in smooth muscle cells by a mitochondrial redox sensor. Circ Res 91: 478-486.

49. Fan F, Ma A, Guan Y, Huo J, Hu Z, et al. (2011) Effect of PGE2 on DA tone by EP4 modulating $\mathrm{Kv}$ channels with different oxygen tension between preterm and term. Int J Cardiol 147: 58-65.

50. Archer SL, Wu XC, Thébaud B, Moudgil R, Hashimoto K, et al. (2004) O2 sensing in the human ductus arteriosus: redox-sensitive $\mathrm{K}+$ channels are regulated by mitochondria-derived hydrogen peroxide. Biol Chem 385: 205216

51. Thébaud B, Michelakis ED, Wu XC, Moudgil R, Kuzyk M, et al. (2004) Oxygensensitive Kv channel gene transfer confers oxygen responsiveness to preterm rabbit and remodeled human ductus arteriosus: implications for infants with patent ductus arteriosus. Circulation 110: 1372-1379.

52. Kajino H, Chen YQ, Seidner SR, Waleh N, Mauray F, et al. (2001) Factors that increase the contractile tone of the ductus arteriosus also regulate its anatomic remodeling. Am J Physiol Regul Integr Comp Physiol 281: R291-301.

53. Waleh N, Reese J, Kajino H, Roman C, Seidner S, et al. (2009) Oxygen-induced tension in the sheep ductus arteriosus: effects of gestation on potassium and calcium channel regulation. Pediatr Res 65: 285-290.

54. Harakalova M, van Harssel JJ, Terhal PA, van Lieshout S, Duran K, et al. (2012) Dominant missense mutations in ABCC9 cause Cantú syndrome. Nat Genet 44: 793-796.

55. Czeschik JC, Voigt C, Goecke TO, Lüdecke HJ, Wagner N, et al. (2013) Wide clinical variability in conditions with coarse facial features and hypertrichosis caused by mutations in ABCC9. Am J Med Genet A 161A: 295-300.

56. Bouayad A, Kajino H, Waleh N, Fouron JC, Andelfinger G, et al. (2001) Characterization of PGE2 receptors in fetal and newborn lamb ductus arteriosus. Am J Physiol Heart Circ Physiol 280: H2342-2349.

57. Park WS, Ko EA, Han J, Kim N, Earm YE (2005) Endothelin-1 acts via protein kinase $\mathrm{C}$ to block KATP channels in rabbit coronary and pulmonary arterial smooth muscle cells. J Cardiovasc Pharmacol 45: 99-108.

58. Sun F, Hayama E, Katsube Y, Matsuoka R, Nakanishi T (2010) The role of the large-conductance voltage-dependent and calcium-activated potassium $(\mathrm{BK}(\mathrm{Ca}))$ channels in the regulation of rat ductus arteriosus tone. Heart Vessels 25: $556-564$

59. Barlow RS, El-Mowafy AM, White RE (2000) H(2)O(2) opens BK(Ca) channels via the PLA(2)-arachidonic acid signaling cascade in coronary artery smooth muscle. Am J Physiol Heart Circ Physiol 279: H475-483.

60. Resnik E, Herron J, Fu R, Ivy DD, Cornfield DN (2006) Oxygen tension modulates the expression of pulmonary vascular BKCa channel alpha- and beta-subunits. Am J Physiol Lung Cell Mol Physiol 290: L761-761L768.

61. Moonen RM, Agren P, Cogolludo AL, Perez Vizcaino F, Villamor E (2010) Response of chicken ductus arteriosus to hypercarbic and normocarbic acidosis. Neonatology 98: 47-56.

62. Takizawa T, Oda T, Arishima K, Yamamoto M, Masaoka T, et al. (1994) A calcium channel blocker verapamil inhibits the spontaneous closure of the ductus arteriosus in newborn rats. J Toxicol Sci 19: 171-174.

63. Yokoyama U, Minamisawa S, Adachi-Akahane S, Akaike T, Naguro I, et al. (2006) Multiple transcripts of Ca2+ channel alpha1-subunits and a nove spliced variant of the alpha1C-subunit in rat ductus arteriosus. Am J Physio Heart Circ Physiol 290: H1660-1670.

64. Akaike T, Jin MH, Yokoyama U, Izumi-Nakaseko H, Jiao Q, et al. (2009) T-type $\mathrm{Ca} 2+$ channels promote oxygenation-induced closure of the rat ductus arteriosus not only by vasoconstriction but also by neointima formation. J Bio Chem 284: 24025-24034.

65. Clyman RI, Waleh N, Kajino H, Roman C, Mauray F (2007) Calcium-dependent and calcium-sensitizing pathways in the mature and immature ductus arteriosus. Am J Physiol Regul Integr Comp Physiol 293: R1650-1656.

66. Hong H, Chen H, Gao W, Cai X, Sun Y, et al. (2009) Hypoxia-induced cytosolic calcium decrease is mediated primarily by the forward mode of $\mathrm{Na}(+) / \mathrm{Ca}(2+)$ exchanger in smooth muscle cells of fetal ductus arteriosus. Pediatr Cardiol 30: $958-964$.

67. Keck M, Resnik E, Linden B, Anderson F, Sukovich DJ, et al. (2005) Oxygen increases ductus arteriosus smooth muscle cytosolic calcium via release of 
Citation: Akaike T, Minamisawa S (2014) Role of Ion Channels in Ductus Arteriosus Closure. Human Genet Embryol 3: 116. doi:10.4172/21610436.1000116

Page 6 of 6

calcium from inositol triphosphate-sensitive stores. Am J Physiol Lung Cell Mol Physiol 288: L917-923.

68. Clapham DE, Runnels LW, Strübing C (2001) The TRP ion channel family. Nat Rev Neurosci 2: 387-396.
69. Lu W, Wang J, Shimoda LA, Sylvester JT (2008) Differences in STIM1 and TRPC expression in proximal and distal pulmonary arterial smooth muscle are associated with differences in Ca2+ responses to hypoxia. Am J Physiol Lung Cell Mol Physiol 295: L104-113. 